University of Nebraska - Lincoln

DigitalCommons@University of Nebraska - Lincoln

USDA National Wildlife Research Center - Staff Publications
U.S. Department of Agriculture: Animal and Plant Health Inspection Service

2013

\title{
Functional significance of ultraviolet feeding cues in wild turkeys
}

\author{
Scott J. Werner \\ USDA-APHIS-Wildlife Services, scott.j.werner@aphis.usda.gov \\ Richard Buchholz \\ Shelagh K. Tupper \\ USDA-APHIS, Wildlife Services' National Wildlife Research Center, shelagh.t.deliberto@usda.gov \\ Susan E. T. Pettit \\ University of Mississippi \\ Jeremy W. Ellis \\ USDA-APHIS, Wildlife Services' National Wildlife Research Center
}

Follow this and additional works at: https://digitalcommons.unl.edu/icwdm_usdanwrc

Werner, Scott J.; Buchholz, Richard; Tupper, Shelagh K.; Pettit, Susan E. T.; and Ellis, Jeremy W., "Functional significance of ultraviolet feeding cues in wild turkeys" (2013). USDA National Wildlife Research Center Staff Publications. 1248.

https://digitalcommons.unl.edu/icwdm_usdanwrc/1248

This Article is brought to you for free and open access by the U.S. Department of Agriculture: Animal and Plant Health Inspection Service at DigitalCommons@University of Nebraska - Lincoln. It has been accepted for inclusion in USDA National Wildlife Research Center - Staff Publications by an authorized administrator of DigitalCommons@University of Nebraska - Lincoln. 


\section{Functional significance of ultraviolet feeding cues in wild turkeys}

\section{Q1 Scott J. Werner ${ }^{\mathrm{a}, *}$, Richard Buchholz ${ }^{\mathrm{b}}$, Shelagh K. Tupper ${ }^{\mathrm{a}}$, Susan E. Pettit ${ }^{\mathrm{a}}$, Jeremy W. Ellis ${ }^{\mathrm{a}}$}

Q2 a USDA/APHIS/WS/National Wildlife Research Center, 4101 LaPorte Avenue, Fort Collins, CO 80521-2154, United States

b University of Mississippi, Biology Department, 104 Shoemaker Hall, University, MS 38677-1848, United States

\section{H I G H L I G H T S}

- Wild turkeys do not prefer UV feeding cues regardless of feeding experience.

- UV feeding cues are used functionally for avian foraging behavior.

- Postingestive consequences are necessary for conditioned avoidance of UV feeding cues.

- Intestinal parasite infection influences the process of food selection in wild turkeys.

\section{A R T I C L E I N F O}

\section{Article history:}

Received 4 November 2012

Received in revised form 15 October 2013

Accepted 18 October 2013

Available online $\mathrm{xxxx}$

\section{Keywords:}

Conditioned avoidance

Eimeria spp.

Foraging behavior

Meleagris gallopavo

Postingestive consequence

Visual cue

\section{G R A P H I C A L A B S T RACT}

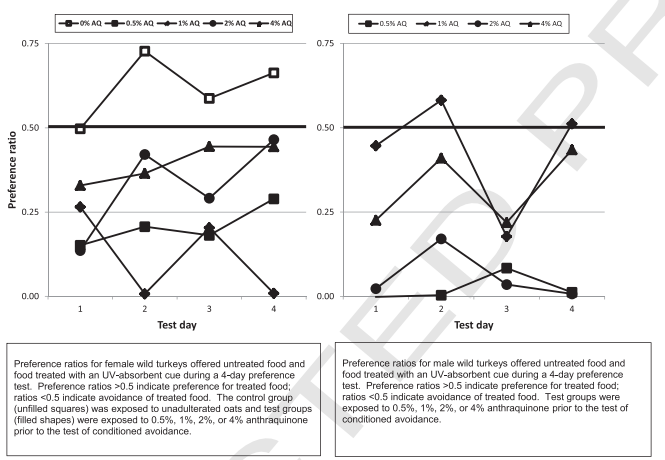


particularly in the context of foraging. Ultraviolet cues could be used for foraging in two ways: 1 ) to detect foraging patches and recognize individual food items, and 2) to assess the relative quality of food items [2]. Comparative studies have found that not all bird species that could benefit from the use of UV feeding cues have evolved the retinal color receptors to do so (e.g. plunge-diving seabirds; [3]). Intraspecific studies have demonstrated that some bird species do indeed use UV cues to detect their food. Diurnal, predatory birds such as the Eurasian kestrel (Falco tinnunculus), rough-legged buzzard (Buteo lagopus) [4] and the great gray shrike (Lanius excubitor; [5]) use the UV reflectance of rodent urine to choose foraging patches where they are more likely to find these prey. Similarly, blue tits (Parus caeruleus) are able to find the first of a set of experimentally hidden cabbage moth (Mamestra brassicae) caterpillars more quickly with UV illumination than without it [6].

Many of the fruits eaten by birds exhibit high UV contrast with their backgrounds $[7,8]$. In a field study where UV filters were placed over Psychotria emetica, a tropical understory shrub, fewer fruits were taken when UV irradiance onto fruits was blocked compared to when UV transmitting filters were used [9]. Of course birds are not the only taxa to rely upon UV cues to detect their food. Predatory jumping spiders (Portia labiata) are preferentially attracted to the webs of their prey spider (Argiope versicolor), but only when the web reflects UV wavelengths [10]. Thus, birds and other animals can detect food more easily using UV cues. It is not clear, however, if birds use UV cues to assess the quality of their food.

Although both the strength of UV reflectance and predator preferences are often positively associated with specific prey, it is not known if preferences associated with UV reflectance increase the lifetime fitness of the forager. Are UV-reflecting prey more nutritious (sensu lato)? For example, are the prey biases observed among kestrels, for male rodents and for certain rodent species (see review; [2]), simply due to differences in signal detectability (i.e. greater UV reflectance) or have these predators learned that prey that exhibit greater UV reflectance provide greater benefits (e.g. more fat resources or fewer parasites)? Unfortunately very little is known about how birds utilize UV feeding cues; are there innate preferences for UV-reflecting or UVabsorbing food, or do birds learn to associate UV cues with food quality?

Ecologically-relevant, newborn color preferences and ontogenetic changes in color preferences have been studied experimentally in birds using only human-perceived colors (400-700 nm). Because of their experimental tractability, most of these studies have used domestic fowl (Gallus gallus domesticus) chicks as study subjects. Newborn domestic chicks prefer food items that are red or green in color if they are fruit-shaped, but avoid red items that are insect-shaped [11]. Chicks learn more easily to avoid distasteful food items that are red or yellow [12], or that contrast with their background [13], but some combinations of color and palatability are difficult for them to learn. For example, chicks require exposure to high quinine concentrations in their prey to learn that purple is unpalatable, but low quinine levels are sufficient for them to learn to avoid distasteful green prey [13].

Ontogenetic differences have been observed in UV foraging preference in redwings (Turdus iliacus; [14]). They discovered that wildcaught adult redwings preferred UV-reflecting bilberry (Vaccinium myrtillus) fruits over bilberries whose UV-reflecting waxy coat had been removed, but only when UV illumination was provided. Naïve, captive-reared redwing juveniles, however, showed no preference for the UV-reflecting fruits in either lighting regime, suggesting that redwings must learn to prefer UV wavelengths (or that their UV perception develops later in life). Ripe fruits often reflect more UV wavelengths [9], possibly explaining why many birds are attracted positively to UV wavelengths. Alternatively, plants may have co-opted existing avian preferences for UV-reflecting mates through sensory exploitation [15] in order to achieve greater seed dispersal by avian frugivores. Others posit that UV wavelengths have no special "meaning" via sensory bias [16], but are simply another color for which birds must learn context dependency (just as birds must learn that some red fruits are unpalat- 137 able; [17]). To better understand how birds can use UV feeding cues, 138 we experimentally investigated the foraging behavior of avian subjects 139 with UV vision.

We used the wild turkey (Meleagris gallopavo) to investigate the 141 functional significance of UV feeding cues. Wild turkeys are omnivores 142 who consume a wide variety of vegetation, fruits, seeds, insects and 143 other invertebrates [18]. Several lines of evidence support our conten- 144 tion that UV vision is important to turkey natural history. First, domestic 145 turkeys (M. gallopavo) are attracted to housing with UV lighting [19]. 146 Second, although they lack UV-sensitive opsin photopigments, ocular 147 oil droplets associated with their short-wavelength sensitive cones ap- 148 parently permit UV vision [20]. Domestic turkeys have considerable 149 sensitivity to wavelengths in the UV-A spectral range (315-400 nm; 150 [20]). Increment threshold psychophysiological tests have shown that 151 domestic turkey poults are maximally sensitive to the UV spectrum at 152 $380 \mathrm{~nm}$ [16]. Other studies have demonstrated that UV vision is proba- 153 bly of relevance to the social and sexual interactions of turkeys as well. 154 The intensity of the UV reflectance of iridescent feathers from male wild 155 turkeys is condition-dependent [21] and the plumage of domestic 156 turkey poults exhibits UV-reflective patterning that is associated with 157 body sites of harmful pecking in commercial poultry houses [22]. More- 158 over, another wild species in the order Galliformes, the black grouse 159 (Tetrao tetrix), prefers UV-reflecting morphs of a fruit that is a seasonally 160 important component of their diet [23].

Because the implications of UV cues are poorly understood for avian 162 foraging behavior, we compared the feeding response of conditioned 163 and unconditioned wild turkeys offered food treated with an UV- 164 absorbent cue subsequent to conditioning with an UV-absorbent, 165 postingestive repellent. If wild birds prefer foods associated with UV 166 wavelengths regardless of feeding experience (hypothesis 1), then con- 167 ditioned and unconditioned wild turkeys will prefer foods treated with 168 an UV cue. If UV feeding cues, like other visual and gustatory cues 169 $[24,25]$, are used functionally for avian foraging behavior (hypothesis 170 2), then wild turkeys conditioned with an UV-absorbent, postingestive 171 repellent will subsequently avoid food treated with an UV-absorbent 172 cue, even in the absence of the aversive consequence.

173

Although intestinal parasite infection (e.g. Eimeria spp.) decreases 174 food consumption in domestic turkeys [26-29], the effects of body con- 175 dition and parasite load are poorly understood for the process of food 176 selection. Coccidia infection influences sexual selection among female 177 wild turkeys [30] and UV plumage signaling among male wild turkeys 178 [21]. Body condition or parasite infection of wild turkeys may also influ- 179 ence an individual's selection of food treated with an UV cue previously 180 paired with negative postingestive consequences. If body condition or 181 parasite infection influences the process of avian food selection (hy- 182 pothesis 3 ), then consumption of food treated with an aversively- 183 conditioned UV cue will be least among wild turkeys with poor body 184 condition or high parasite infection.

\section{Feeding experiments}

\subsection{Subjects and testing facilities}

187

Wild turkeys (4-6 years of age) were maintained at the Department 188 of Biology's Avian Research Facility at the University of Mississippi Field 189 Station in Lafayette County, Mississippi, USA. The wild turkey flock of 190 game farm origin was raised in captivity from hatching. Twenty netted 191 enclosures $(4.0 \times 3.7 \times 1.8 \mathrm{~m})$ were established within a 0.04-ha flight 192 pen for the study of hens (i.e. female wild turkeys; body mass 193 average $=4.07 \mathrm{~kg}$, range $=3.02-5.75 \mathrm{~kg}$ ). We used 16 individual 194 cages $(2.4 \times 1.5 \times 1.8 \mathrm{~m})$ within an open-sided research aviary for the 195 study of gobblers (male wild turkeys; body mass average $=9.87 \mathrm{~kg}, 196$ range $=7.45-11.50 \mathrm{~kg}$ ). Clean water was provided ad libitum to all 197 test subjects throughout the study. 


\subsection{Experimental procedures}

Experimental investigation of foraging behavior requires that test subjects be exposed to ecologically relevant feeding conditions, but scientific ethics require that we minimize and mitigate the pain and distress of test subjects. In concert with the university veterinarian, we developed a protocol to meet both of these scientific needs. In the weeks prior to our study, all test subjects were offered a balanced poultry ration ad libitum to ensure that they were in the best condition for our study. We delayed our study until all test subjects had completed their molt. We paired hens within test cages to alleviate distress of individuals and disruption of flock dominance. We selected concentrations of test materials that had been previously approved for and tested with wild birds [31-33] to effectively condition and test avoidance whilst minimizing exposure among test subjects. The health of all subjects was monitored daily by study personnel and university animal care staff. Veterinary intervention due to our experimental procedures was never necessary. In accordance with U.S. federal law, all procedures were conducted only after review by and approval from the University of Mississippi's Institutional Animal Care and Use Committee (protocol \#12-001; R. Buchholz - Study Director).

\subsubsection{Conditioned avoidance of an UV-absorbent feeding cue}

A titanium dioxide cue (Aeroxide ${ }^{\circledR}$ P25; Acros Organics, Fair Lawn, 263 NJ, U.S.A.) was used to test food avoidance previously conditioned 264 with the anthraquinone-based repellent. We previously used spectro- 265 photometry to determine that this titanium dioxide cue absorbs UV 266 wavelengths similarly to Avipel repellent [33] and throughout the spec- 267 trum visible to M. gallopavo.

Two bowls ( $1 \mathrm{~kg}$ oats per bowl for hens, $0.5 \mathrm{~kg}$ oats per bowl for 269 gobblers) were offered in each cage at approximately $0800 \mathrm{~h}$, daily, dur- 270 ing the four days subsequent to repellent exposure. One bowl contained 271 untreated oats. The alternate bowl contained oats treated only with the 272 UV-absorbent cue (0.2\% titanium dioxide, wt./wt.; [33]). We formulated 273 oat treatments by applying aqueous suspensions ( $85 \mathrm{ml}$ suspension $/ \mathrm{kg}$ ) 274 to whole oats using a rotating mixer and household spray equipment. 275 The east-west placement of treated and untreated oats was randomized 276 on test day one, and was thereafter alternated daily, throughout the 277 test. Daily consumption of treated and untreated oats was indepen- 278 dently measured within each cage, including spillage, at approximately 279 $0800 \mathrm{~h}$ throughout the test of conditioned avoidance.

\subsection{Analytical chemistry}

281

Reversed-phase, high performance liquid chromatography (HPLC) 282 with UV detection (254 nm) was used to quantify anthraquinone resi- 283 dues for all repellent-treated oats ( $\pm 100 \mathrm{ppm}$ anthraquinone). We col- 284 lected a $200 \mathrm{~g}$ sample of each treatment used for repellent exposure. 285 Subsequent to formulations, all samples were transferred to a $4{ }^{\circ} \mathrm{C}$ re- 286 frigerator at the National Wildlife Research Center (Fort Collins, CO, 287 U.S.A.) where they were stored for the duration of the analysis period. 288

Triplicate subsamples from each repellent treatment were extracted 289 and analyzed. All samples were cryogenically homogenized. Control 290 samples were fortified with $1,500 \mathrm{ppm}$ and 40,000 ppm anthraqui- 291 none, and extracted to determine the recovery rate for the assay. We 292 weighed $0.5( \pm 0.05) \mathrm{g}$ of ground whole oats into $25-\mathrm{ml}$ glass test 293 tubes fitted with Teflon lined caps. We pipetted $8 \mathrm{ml}$ of $25 \%$ hexane in 294 chloroform ( $\mathrm{vol} / \mathrm{vol})$ into each tube. Extraction was accomplished by 295 vortexing each tube for $20 \mathrm{~s}$, placing on a horizontal shaker for 296 $30 \mathrm{~min}$, sonicating for $30 \mathrm{~min}$, and then centrifuging at 2,000 rpm for 297 $10 \mathrm{~min}$. The supernatant was carefully filtered through a $0.45 \mu \mathrm{m}$ Teflon 298 filter into a 25-ml volumetric flask. The entire extraction procedure was 299 replicated three times and the supernatants were combined. The sam- 300 ple was diluted to volume with the $25 \%$ hexane in chloroform solution 301 and an aliquot was placed in a clean $25-\mathrm{ml}$ glass test tube. The aliquot 302 was evaporated to dryness at $50{ }^{\circ} \mathrm{C}$ under a gentle stream of nitrogen. 303 The extract was reconstituted using $10 \mathrm{ml}$ of methanol, sonicated for 304 $30 \mathrm{~min}$, and again centrifuged at 2,000 rpm for $10 \mathrm{~min}$. Sample solu- 305 tions were transferred into autosampler vials and analyzed by HPLC 306 using an Agilent 1200 liquid chromatograph (Agilent Technologies, 307 Inc., Santa Clara, CA, U.S.A.).

The HPLC instrument included a Waters X-Bridge Phenyl column 309 $(2.5 \mu \mathrm{m}, 2.1 \times 50 \mathrm{~mm})$. The mobile phase gradient included $90 \% 310$ Millipore water and 10\% methanol at 0 and $2 \mathrm{~min}$, 20\% Millipore 311 water and $80 \%$ methanol at 4 and $7 \mathrm{~min}$, and 100\% methanol at 312 $10 \mathrm{~min}$. The HPLC flow rate, injection volume, and temperature were 313 $0.3 \mathrm{ml} / \mathrm{min}, 5 \mu \mathrm{l}$ and $40{ }^{\circ} \mathrm{C}$, respectively. A four-point external calibra- 314 tion curve was used to calibrate our HPLC instrument. Samples were 315 run in triplicate each day and we checked single calibration points 316 upon each ten injections. The average response was plotted against an- 317 thraquinone concentrations. Linear regression was used to calculate an- 318 thraquinone concentrations among samples.

\subsection{Statistical analyses}

The dependent measure for the repellent exposure phase of our study 321 was calculated as test consumption of anthraquinone-treated oats rela- 322 tive to average pre-test consumption of untreated oats (i.e. percent 323 
repellency $=\left(1-\left(\right.\right.$ test consumption $\times$ pre-test consumption $\left.\left.{ }^{-1}\right)\right) \times$ $100 ;[31,32])$. Logarithmic regression procedures (SAS v9.2) were used to analyze repellency as a function of actual anthraquinone concentration $( \pm 100 \mathrm{ppm})$ and predict a threshold anthraquinone concentration (i.e. 80\% repellency; [31,32]) for hens and gobblers. Descriptive statistics $(\bar{x} \pm \mathrm{SE})$ were used to summarize oat and anthraquinone consumption during repellent exposure.

The dependent measure for the test of conditioned avoidance was average daily consumption of untreated oats and oats treated with the UV-absorbent cue throughout the test. Test consumption data for hens and gobblers were subjected to a repeated measures ANOVA. The random effect of our model was cages (i.e. paired hens, individual gobblers), the between-subjects effects were oat treatments (treated, untreated) and test groups (i.e. previous exposure to $0 \%, 0.5 \%, 1 \%, 2 \%$, or $4 \%$ anthraquinone-treated oats), and the within-subject effect was test day. The group-by-treatment interaction was analyzed using the mixed procedure (SAS v9.2). Tukey's tests were used to separate the means of significant interactions $(\alpha=0.05)$, and descriptive statistics $(\bar{x} \pm \mathrm{SE})$ and preference ratios [daily average $\mathrm{TiO}_{2}$ consumption $\times$ (daily average $\mathrm{TiO}_{2}$ consumption + untreated consumption $)^{-1}$ ] were used to summarize and illustrate test consumption, respectively.

To test our prediction regarding the influence of subject body condition, we measured the condition (body mass $\times$ tarsus length $^{-1}$ ) and enumerated intestinal parasites (Eimeria spp., Capillaria spp., other nematodes) from collected fecal samples [30] for each tested gobbler (i.e. independent of test groups; $n=16$ ). Body condition and parasite data were not available for individual hens that were paired for our feeding experiments. These indices of body condition were correlated with 4-day average test consumption and relative test consumption [4-day average $\mathrm{TiO}_{2}$ consumption $\times$ (4-day average $\mathrm{TiO}_{2}$ consumption + untreated consumption $)^{-1}$ ] of food treated with the UV cue during the test of conditioned avoidance.

\section{Results}

\subsection{Exposure to an $U V$-absorbent, postingestive repellent}

Hens in the control group consumed $216.1 \pm 21.0 \mathrm{~g}$ of untreated oats during the exposure phase of our study; their average, pre-test consumption of untreated oats was $193.3 \pm 22.5 \mathrm{~g}$. In contrast, hens exposed to oats treated with $0.5-4 \%$ anthraquinone exhibited $75-98 \%$ repellency during repellent exposure (Table 1 ). Hen repellency (y) was a function of anthraquinone concentration (x): $y=10.746$ $\ln (\mathrm{x})-12.029\left(r^{2}=0.94, P=0.030\right)$. We therefore predicted a threshold concentration of 5,300 ppm anthraquinone (i.e. $80 \%$ repellency), or $47.0 \pm 18.3 \mathrm{mg}$ anthraquinone $\times \mathrm{kg}$ body mass ${ }^{-1}$, for hens offered treated oats.

Gobblers exposed to oats treated with $0.5-4 \%$ anthraquinone exhibited $78-99 \%$ repellency during repellent exposure (Table 1 ). Gobbler

Table 1

Feeding repellency of oats treated with an anthraquinone-based repellent (Avipel®; Arkion Life Sciences, New Castle, DE, U.S.A.) among wild turkeys, Meleagris gallopavo. Actual anthraquinone concentrations among oat seed treatments were quantified using high performance liquid chromatography. The method detection limit (MDL) of our analyses was $0.50 \mu \mathrm{g}$ anthraquinone/g. Percent repellency represents daily consumption of repellent-treated oats relative to average pre-treatment consumption of untreated oats among five groups of females ( $n=$ four cages of paired hens per group) and four groups of males ( $n=$ four individually-caged gobblers per group).

\begin{tabular}{llll}
\hline $\begin{array}{l}\text { Targeted anthraquinone } \\
\text { concentration (\%) }\end{array}$ & $\begin{array}{l}\text { Actual anthraquinone } \\
\text { concentration }(\mathrm{ppm})\end{array}$ & $\begin{array}{l}\text { Hen } \\
\text { repellency }(\%)\end{array}$ & $\begin{array}{l}\text { Gobbler } \\
\text { repellency }(\%)\end{array}$ \\
\hline 0 & $<$ MDL & -12 & \\
0.5 & 4100 & 75 & 78 \\
1 & 8800 & 89 & 91 \\
2 & 19,100 & 95 & 97 \\
4 & 34,400 & 98 & 99 \\
\hline
\end{tabular}

repellency (y) was a function of anthraquinone concentration (x): 370 $\mathrm{y}=9.921 \ln (\mathrm{x})-2.260\left(r^{2}=0.93, P=0.034\right)$. We therefore pre- 371 dicted a threshold concentration of $4000 \mathrm{ppm}$ anthraquinone, or 372 $13.7 \pm 8.3 \mathrm{mg}$ anthraquinone $\times \mathrm{kg}$ body mass ${ }^{-1}$, for gobblers offered 373 treated oats.

On average, hens and gobblers consumed $114 \pm 88 \mathrm{mg}$ and 375 $48 \pm 15 \mathrm{mg}$ of anthraquinone when exposed to oats treated with $4 \% 376$ anthraquinone, respectively. In comparison, average consumption 377 among hens and gobblers was $204 \pm 34 \mathrm{mg}$ and $129 \pm 38 \mathrm{mg}$ anthra- 378 quinone, respectively, when exposed to oats treated with $0.5 \%, 1 \%$, or $2 \% 379$ anthraquinone. Thus, conditioned food avoidance was positively related 380 to the amount of the postingestive repellent consumed during the one- 381 day exposure.

\subsection{Conditioned avoidance of an UV-absorbent feeding cue}

383

The five test groups of hens consumed different amounts of oats 384 treated with the UV-absorbent cue and untreated oats during the four- 385 day test of conditioned avoidance $\left(F_{9,27}=11.66, P<0.0001\right.$; Fig. 1a). 386 Unconditioned (control) hens consumed similar amounts of untreated 387
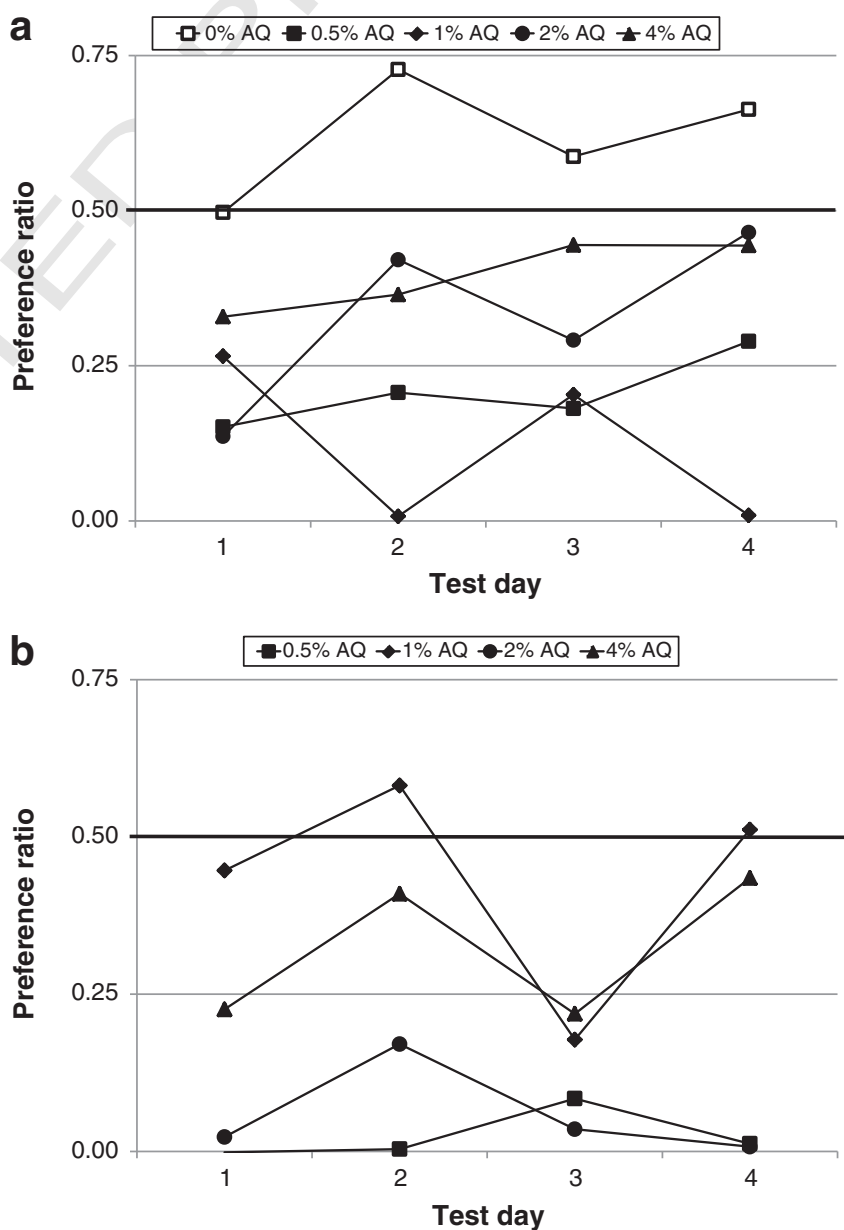

Fig. 1. Preference ratios for (a) five test groups of female wild turkeys (Meleagris gallopavo $n=$ four cages of paired hens per group) and (b) four test groups of male wild turkeys ( $n=$ four individually-caged gobblers per group) offered untreated food and food treated with an UV-absorbent cue (a.i. titanium dioxide; Acros Organics, Fair Lawn, NJ, U.S.A.) subsequent to one-day exposure to an UV-absorbent, postingestive repellent (a.i. 9,10anthraquinone; Arkion Life Sciences, New Castle, DE, U.S.A.). Preference ratios $>0.5$ indicate preference for treated food; ratios $<0.5$ indicate avoidance of treated food. The control group of females (unfilled squares) was exposed to untreated oats and test groups (filled shapes) were exposed to $0.5 \%, 1 \%, 2 \%$, or $4 \%$ anthraquinone ( $\mathrm{AQ}$ wt./wt.) prior to the test of conditioned avoidance. 
oats and oats treated with titanium dioxide throughout the test (Fig. 1a). The control group consumed an average of $138.6 \pm 13.1 \mathrm{~g}$ of oats treated with titanium dioxide and $87.7 \pm 17.5 \mathrm{~g}$ of untreated oats per day (Tukey $P=0.667$ ). Thus, unconditioned wild turkeys did not significantly prefer foods treated with an UV feeding cue.

In contrast, hens conditioned with the UV-absorbent, postingestive repellent subsequently avoided oats treated with the UV-absorbent cue throughout the test (Fig. 1a). Hens previously exposed to oats treated with $0.5 \%$ anthraquinone consumed an average of $51.0 \pm 17.1 \mathrm{~g}$ of oats treated with titanium dioxide and $197.6 \pm 21.5 \mathrm{~g}$ of untreated oats per day (Tukey $P<0.001$ ). The group of hens exposed to oats treated with $1 \%$ anthraquinone subsequently consumed an average of $34.8 \pm 17.9 \mathrm{~g}$ of oats treated with titanium dioxide and $229.7 \pm 26.4 \mathrm{~g}$ of untreated oats per day (Tukey $P<0.0001$ ). Hens previously exposed to oats treated with $2 \%$ anthraquinone consumed an average of $78.3 \pm 16.5 \mathrm{~g}$ of oats treated with titanium dioxide and $173.7 \pm 24.7 \mathrm{~g}$ of untreated oats per day (Tukey $P=0.038$ ). Thus, the UV-absorbent cue was used to maintain avoidance during the four days subsequent to postingestive conditioning.

The group of hens previously exposed to oats treated with $4 \%$ anthraquinone consumed an average of $81.9 \pm 13.7 \mathrm{~g}$ of oats treated with titanium dioxide and $128.1 \pm 14.9 \mathrm{~g}$ of untreated oats per day (Tukey $P=0.774$ ). Thus, conditioned avoidance of food treated with the UV-absorbent cue was influenced by the amount of repellenttreated oats consumed during exposure (i.e. the negative postingestive consequence).

The four test groups of gobblers also consumed different amounts of oats treated with the UV-absorbent cue and untreated oats during the four-day test of conditioned avoidance $\left(F_{7,21}=14.20, P<0.0001\right.$; Fig. 1b). Gobblers previously exposed to oats treated with $0.5 \%$ anthraquinone consumed an average of $4.2 \pm 4.3 \mathrm{~g}$ of oats treated with titanium dioxide and $196.0 \pm 18.6 \mathrm{~g}$ of untreated oats per day (Tukey $P<0.0001$ ). The group of gobblers exposed to oats treated with $1 \%$ anthraquinone subsequently consumed an average of $86.6 \pm 23.6 \mathrm{~g}$ of oats treated with titanium dioxide and $117.4 \pm 28.0 \mathrm{~g}$ of untreated oats per day (Tukey $P=0.961$ ). Two gobblers in the group previously exposed to $1 \%$ anthraquinone consumed more oats treated with the UV-absorbent cue than untreated oats on test days one-four, and test days one, two and four, respectively. Of these two gobblers, one had the highest parasite infection measured in the study [i.e. greatest abundance of Eimeria spp. (203/fecal g), Capillaria spp. (1267/g) and other nematodes $(34 / \mathrm{g})]$ and the other gobbler had an intermediate parasite infection among tested gobblers.

Gobblers previously exposed to oats treated with $2 \%$ anthraquinone consumed an average of $12.4 \pm 7.6 \mathrm{~g}$ of oats treated with titanium dioxide and $206.3 \pm 24.5 \mathrm{~g}$ of untreated oats per day (Tukey $P<0.0001$ ). The group of gobblers exposed to oats treated with $4 \%$ anthraquinone subsequently consumed an average of $77.4 \pm 21.6 \mathrm{~g}$ of oats treated with titanium dioxide and $175.3 \pm 25.8 \mathrm{~g}$ of untreated oats per day (Tukey $P=0.054$ ). Two gobblers in the group previously exposed to $4 \%$ anthraquinone consumed more oats treated with the UV-absorbent cue than untreated oats on test days two and four, and test days two, three and four, respectively. Of these two gobblers, one consumed the least amount $(0.7 \mathrm{~g})$ of $4 \%$ anthraquinone-treated oats during repellent exposure. Similar to the hens, conditioned avoidance of UV-absorbent food was influenced by the amount of repellenttreated oats consumed by tested gobblers during exposure.

With further regard to the relationship between body condition and conditioned avoidance of food treated with an UV cue, we observed moderate, positive correlations [42] between consumption of food treated with the conditioned UV cue and intestinal parasite infection among tested gobblers (Table 2 ). We also observed a weak negative correlation between body condition and intestinal parasite infection (Table 2). Thus, intestinal parasites moderately decreased conditioned avoidance of food treated with an UV cue previously paired with negative postingestive consequences during the gobbler test.
Table 2

Correlation coefficients for empirical relationships between body condition (body t2.2 mass $\times$ tarsus length ${ }^{-1}$ ), intestinal parasite infection (abundance $\times$ fecal g$^{-1}$ ), and test $t 2.3$ consumption and relative test consumption of food treated with an UV cue among male t2.4 wild turkeys, Meleagris gallopavo, used to test conditioned avoidance of food treated t2.5 with an UV cue previously associated with negative postingestive consequences.

\begin{tabular}{|c|c|c|c|c|}
\hline & $\begin{array}{l}\text { Body } \\
\text { condition }\end{array}$ & $\begin{array}{l}\text { Eimeria } \\
\text { spp. }\end{array}$ & $\begin{array}{l}\text { Capillaria } \\
\text { spp. }\end{array}$ & $\begin{array}{l}\text { Other } \\
\text { nematodes }\end{array}$ \\
\hline Consumption of UV-treated food & 0.013 & 0.496 & 0.479 & 0.433 \\
\hline Relative consumption of UV-treated food & -0.002 & 0.519 & 0.503 & 0.452 \\
\hline Eimeria spp. & -0.213 & & & \\
\hline Capillaria spp. & -0.219 & & & \\
\hline Other nematodes & -0.249 & & & \\
\hline
\end{tabular}

\section{Discussion}

Female turkeys exhibited no avoidance of untreated food and 455 $75-98 \%$ avoidance of food treated with an UV-absorbent, postingestive 456 repellent (0.5-4\% anthraquinone; wt./wt.) during one day of repellent 457 exposure. Male turkeys exhibited 78-99\% avoidance of food treated 458 with $0.5-4 \%$ anthraquinone. Hens and gobblers that consumed more 459 than $200 \mathrm{mg}$ and $100 \mathrm{mg}$ of the UV-absorbent, postingestive repellent, 460 respectively, subsequently avoided food treated only with an UV- 461 absorbent cue. Ultraviolet feeding cues were therefore specifically 462 related to the postingestive consequences of the subsequent reinforcer 463 [43]. In contrast, unconditioned hens consumed 58\% more food treated 464 with the UV-absorbent cue than untreated food. Thus, conditioned food 465 avoidance was positively related to the amount of the postingestive re- 466 pellent consumed during the one-day exposure, and the consequences 467 of consuming oats treated with the postingestive, UV-absorbent repel- 468 lent were necessary for conditioned avoidance of the UV-absorbent 469 cue. Wild turkeys do not prefer foods associated with UV wavelengths 470 regardless of feeding experience (hypothesis 1 ).

In the absence of negative postingestive feedback [44,45], UV feed- 472 ing cues are therefore unlikely to function as aposematic signals [46] 473 or elicit food avoidance in wild birds. Ultraviolet foraging behavior is 474 therefore a function of its consequences [47] and UV feeding cues are 475 used functionally for foraging behavior in wild turkeys (hypothesis 2). 476 Subsequent investigations should be focused to relate food preference 477 with the chromatic and achromatic characteristics of natural foods [7]. 478 Newborn and ontogenetic color preferences can be better understood 479 by investigating the full spectrum visible to and used by avian subjects. 480

We predicted that consumption of food treated with an aversively- 481 conditioned UV cue would be least among wild turkeys with poor body 482 condition or high parasite infection (Hypothesis 3 ). Rather, we observed 483 moderate, positive correlations between consumption of food treated 484 with the conditioned UV cue and intestinal parasite infection (Table 2). 485 In context of food selection, aversive feedback or a lack of positive feed- 486 back from the gut to the central nervous system causes animals to reduce 487 food consumption $[44,45]$. Perhaps poor body condition or high parasite 488 infection can interfere with feedback-mediated consumption of foods, 489 including those previously associated with negative postingestive conse- 490 quences. Supplemental studies are recommended to further investigate 491 the influence of parasite infection and subject body condition for the pro- 492 cess of avian food selection.

In conclusion, we discovered that wild turkeys do not prefer foods 494 associated with UV wavelengths regardless of feeding experience. 495 Rather, we found that wild turkeys can use UV feeding cues to avoid 496 foods previously associated with negative postingestive consequences, 497 and that this cue-consequence association was dependent upon the 498 amount of previously experienced, postingestive consequences. Thus, 499 UV feeding cues, like other visual and gustatory cues, have functional 500 significance for avian foraging behavior. Not all individuals in our 501 study, however, exhibited conditioned avoidance of foods treated with 502 an UV feeding cue, an effect moderately related to intestinal parasite in- 503 fection. Our study of the functional use of UV feeding cues in wild 504 
turkeys contributes to a broader avian data set and will enable subsequent investigations regarding the sensory physiology and behavioral ecology of wild birds.

\section{Acknowledgments}

We thank M. L. Avery, B. F. Blackwell, B. A. Kimball, G. M. Linz, F. D. Provenza, and M. E. Tobin for their thoughtful review of our manuscript. P. B. Fioranelli (Mississippi Field Station - National Wildlife Research Center, Starkville, MS, U.S.A.) provided dedicated assistance with constructing and disassembling enclosures for our hen study. We also thank the analytical chemistry unit at the National Wildlife Research Center (Fort Collins, CO, U.S.A.) for performing anthraquinone residue analyses. Arkion Life Sciences (New Castle, DE, U.S.A.) provided the Avipel ${ }^{\circledR}$ repellent and Acros Organics (Fair Lawn, NJ, U.S.A.) provided the Aeroxide ${ }^{\circledR}$ P25 for our study. Corporate collaborations do not imply endorsement by the United States Department of Agriculture. This project was supported in part by California Department of Food and Agriculture's Specialty Crop Block Grant to S.J.W. (Grant Agreement SCB10034).

\section{References}

[1] Aidala Z, Huynen L, Brennan PLR, Musser J, Fidler A, Chong N, et al. Ultraviolet visual sensitivity in three avian lineages: paleognaths, parrots, and passerines. J Comp Physiol A 2012;198:495-510.

[2] Honkavaara J, Koivula M, Korpimäki E, Siitari H, Viitala J. Ultraviolet vision and foraging in terrestrial vertebrates. Oikos 2002;98:505-11.

[3] Håstad O, Ernstdotter E, Odeen A. Ultraviolet vision and foraging in dip and plunge diving birds. Biol Lett 2005;1:306-9.

[4] Viitala J, Korpimaki E, Palokangas P, Koivula M. Attraction of kestrels to vole scent marks visible in ultraviolet light. Nature 1995;373:425-7.

[5] Probst R, Pavlicev M, Viitala J. UV reflecting vole scent marks attract a passerine, the great grey shrike (Lanius excubitor). J Avian Biol 2002;33:437-40.

6] Church SC, Bennett ATD, Cuthill IC, Partridge JC. Ultraviolet cues affect the foraging behaviour of blue tits. Proc R Soc Lond B 1998;265:1509-14.

[7] Schaefer HM, Levey DJ, Schaefer V, Avery ML. The role of chromatic and achromatic signals for fruit detection by birds. Behav Ecol 2006;17:784-9.

[8] Schaefer HM, McGraw K, Catoni C. Birds use fruit colour as honest signal of dietary antioxidant rewards. Funct Ecol 2008;22:303-10.

[9] Altshuler DL. Ultraviolet reflectance in fruits, ambient light composition and fruit removal in a tropical forest. Evol Ecol Res 2001;3:767-78.

[10] Zou Y, Araujo DP, Lim MLM, Li D. Ultraviolet is a more important cue than reflection in other wavelengths for a jumping spider to locate its spider prey. Anim Behav 2011;82:1457-63.

[11] Gamberale-Stille G, Tullberg BS. Fruit or aposematic insect? Context-dependent colour preferences in domestic chicks. Proc Biol Sci 2001;268:2525-9.

[12] Rowe C, Skelhorn J. Colour biases are a question of taste. Anim Behav 2005;69:587-94.

[13] Halpin CG, Skelhorn J, Rowe C. Being conspicuous and defended: selective benefits for the individual. Behav Ecol 2008;19:1012-7.

[14] Siitari H, Honkavaara J, Viitala J. Ultraviolet reflection of berries attracts foraging birds. A laboratory study with redwings (Turdus iliacus) and bilberries (Vaccinium myrtillus). Proc R Soc Lond 1999;266:2125-9.

[15] Bennet ATD, Théry M. Avian color vision and coloration: multidisciplinary evolutionary biology. Am Nat 2007;169:S1-6.

[16] Barber CL, Prescott NB, Jarvis JR, Le Sueur C, Perry GC, Wathes CM. Comparative study of the photopic spectral sensitivity of domestic ducks (Anas platyrhynchos domesticus), turkeys (Meleagris gallopavo gallopavo) and humans. Br Poultry Sci 2006;47:365-74.

[17] Lev-Yadun S, Ne'eman G, Izhaki I. Unripe red fruits may be aposematic. Plant Signal Behav 2009;4:836-41.
[18] Hurst GA. Foods and feeding. In: Dickson JG, editor. The wild turkey: biology and 563 management. Harrisburg, PA: Stackpole Books; 1992. p. 66-83. 564

[19] Moinard C, Sherwin CM. Turkeys prefer fluorescent light with supplementary ultra- 565 violet radiation. Appl Anim Behav Sci 1999;64:261-7. 566

[20] Hart NS, Partridge JC, Cuthill IC. Visual pigments, cone oil droplets, ocular media and 567 predicted spectral sensitivity in the domestic turkey (Meleagris gallopavo). Vision 568 Res 1999;39:3321-8. 569

[21] Hill GE, Doucet SM, Buchholz R. The effect of coccidial infection on iridescent plum- 570 age coloration in wild turkeys. Anim Behav 2005;69:387-94. 571

[22] Sherwin CM, Devereux CL. A preliminary investigation of ultraviolet-visible markings 572 in domesticated turkey chicks and a possible role in injurious pecking. Br Poultry Sci 573 1999;40:429-33.

[23] Siitari H, Viitala J, Hovi M. Behavioural evidence for ultraviolet vision in a tetraonid 575 species - foraging experiment with black grouse (Tetrao tetrix). J Avian Biol 576 2002;33:199-202.

[24] Werner SJ, Kimball BA, Provenza FD. Food color, flavor, and conditioned avoidance 578 among red-winged blackbirds. Physiol Behav 2008;93:110-7. 579

[25] Werner SJ, Provenza FD. Reconciling sensory cues and varied consequences of avian 580 repellents. Physiol Behav 2011:102:158-63. 581

[26] Clarkson MJ. The life history and pathogenicity of Eimeria meleagrimitis Tyzzer 1929, 582 in the turkey poult. Parasitology 1959;49:70-82. 583

[27] Hein H. Eimeria adenoeides and E. meleagrimitis: pathogenic effect in turkey poults. 584 Exp Parasitol 1969;24:163-70. 585

[28] Yvore P, Berdougo H, Naciri M, Bree A, Lafont JP. Pathogenic study of turkey coccidiosis 586 due to Eimeria adenoeides. Ann Rech Vet 1978;9:531-9. 587

[29] Augustine PC, Thomas OP. Eimeria meleagrimitis in young turkeys: effects on weight, 588 blood, and organ parameters. Avian Dis 1979;23:854-62. 589

[30] Buchholz R. Effects of parasitic infection on mate sampling by female wild turkeys 590 (Meleagris gallopavo): should infected females be more or less choosy? Behav Ecol 591 2004;15:687-94.

[31] Werner SJ, Carlson JC, Tupper SK, Santer MM, Linz GM. Threshold concentrations of 593 an anthraquinone-based repellent for Canada geese, red-winged blackbirds, and 594 ring-necked pheasants. Appl Anim Behav Sci 2009;121:190-6. 595

[32] Werner SJ, Linz GM, Carlson JC, Pettit SE, Tupper SK, Santer MM. Anthraquinone- 596 based bird repellent for sunflower crops. Appl Anim Behav Sci 2011;129:162-9. 597

[33] Werner SJ, Tupper SK, Carlson JC, Pettit SE, Ellis JW, Linz GM. The role of a general- 598 ized ultraviolet cue for blackbird food selection. Physiol Behav 2012;106:597-601. 599

[34] Fraser CM, editor. The Merck veterinary manual. 7th ed. Rahway, NJ: Merck \& 600 Company, Inc.; 1991.

[35] Avery ML, Humphrey JS, Decker DG. Feeding deterrence of anthraquinone, anthra- 602 cene, and anthrone to rice-eating birds. J Wildl Manag 1997;61:1359-65. 603

[36] Avery ML, Humphrey JS, Primus TM, Decker DG, McGrane AP. Anthraquinone pro- 604 tects rice seed from birds. Crop Prot 1998;17:225-30. 605

[37] Cummings JL, Avery ML, Mathre O, Wilson EA, York DL, Engeman RM, et al. Field 606 evaluation of Flight Control ${ }^{\mathrm{TM}}$ to reduce blackbird damage to newly planted rice. 607 Wildl Soc Bull 2002;30:816-20. 608

[38] Cummings JL, Byrd RW, Eddleman WR, Engeman RM, Tupper SK. Effectiveness of 609 AV-1011® to reduce damage to drill-planted rice from blackbirds. J Wildl Manag 610 2011;75:353-6.

[39] Dolbeer RA, Seamans TW, Blackwell BF, Belant JL. Anthraquinone formulation (Flight 612 Control $^{\mathrm{TM}}$ ) shows promise as an avian feeding repellent. J Wildl Manag 613 1998;62:1558-64.

[40] Blackwell BF, Seamans TW, Dolbeer RA. Plant growth regulator (Stronghold ${ }^{\mathrm{TM}}$ ) 615 enhances repellency of anthraquinone formulation (Flight Control ${ }^{\mathrm{TM}}$ ) to Canada 616 geese. J Wildl Manag 1999;63:1336-43.

[41] Blackwell BF, Helon DA, Dolbeer RA. Repelling sandhill cranes from corn: whole- 618 kernel experiments with captive birds. Crop Prot 2001;20:65-8. 619

[42] Cohen J. Statistical power analysis for the behavioral sciences. 2nd ed. Hillsdale, NJ: 620 Lawrence Erlbaum Associates, Publishers; 1988. 621

[43] Garcia J, Koelling RA. Relation of cue to consequence in avoidance learning. Psychon 622 Sci 1966;4:123-4 623

[44] Provenza FD. Postingestive feedback as an elementary determinant of food prefer- 624 ence and intake in ruminants. J Range Manage 1995;48:2-17. 625

[45] Provenza FD, Villalba JJ. Foraging in domestic vertebrates: linking the internal and 626 external milieu. In: Bels VL, editor. Feeding in domestic vertebrates: from structure 627 to function. Oxfordshire: CABI; 2006. p. 210-40. 628

[46] Lyytinen A, Alatalo RV, Lindstrom L, Mappes J. Can ultraviolet cues function as 629 aposematic signals? Behav Ecol 2001:12:65-70.

[47] Skinner BF. Selection by consequences. Science 1981;213:501-4. 631 